\title{
Charge matters
}

\author{
Thomas Laue ${ }^{1}$
}

Received: 29 September 2016 / Accepted: 30 September 2016/Published online: 20 October 2016

(C) International Union for Pure and Applied Biophysics (IUPAB) and Springer-Verlag Berlin Heidelberg 2016

I first read Don Winzor's papers in the early 1970s while a graduate student in Gary Acker's and David Yphantis's labs. Don's interest in developing methods for characterizing protein-protein interactions matched those labs' interests, particularly with respect to chromatography and analytical ultracentrifugation. Over the years, I had the opportunity to meet Don at various conferences, mostly in Australia, and to discuss the sources and measurement of thermodynamic nonideality. Imagine my surprise, then, when one afternoon in the 1990s, I looked up to find Don standing in the doorway of my office at the University of New Hampshire (UNH). It turned out that one of his daughters was working on her chemistry $\mathrm{PhD}$ at $\mathrm{UNH}$, and Don was paying her a visit as part of an around-theworld tour. A seminar was hastily arranged, and we had him over for supper. Over the next few years, Don would occasionally visit his daughter, always dropping by my office to chat about his latest work. He never announced his visits - it was as though he lived in the next town and just wanted to stop in to say hello. Our chats focused on protein-protein interactions and the role of nonideality in governing them.

While our talks would delve into the specifics of certain systems we were studying, they often touched on the larger and more general questions concerning highconcentration thermodynamics in biology. How do

This article is part of a Special Issue on "Analytical Quantitative Relations in Biochemistry" edited by Damien Hall and Stephen Harding.

Thomas Laue

Tom.Laue@unh.edu

1 Department of Molecular, Cellular and Biomedical Sciences, University of New Hampshire, Durham, NH 03824, USA proteins remain soluble, yet interact specifically in complex, high-concentration fluids like cell cytosol or plasma? What gives rise to the quinary (McConkey 1982; Monteith et al. 2015) structure of the cytosol? What molecular characteristics would be most important when trying to develop a high-concentration biopharmaceutical formulation?

Simple calculations revealed that charge-charge interactions between molecules could potentially contribute far more to thermodynamic nonideality than excluded volume interactions. Importantly, charge interactions may be either repulsive (same-sign charges) or attractive (opposite-sign charges), while excluded volume interactions are only repulsive. The observation that charge-charge interactions may be both repulsive or attractive suggests the possibility that, on average, a central molecule will have nearest-neighbors with which it has the most favorable interactions, while those with which it has less favorable interactions will be repelled, thus contributing to the quinary structure of the fluid. Furthermore, the unequal distribution of charge on proteins can lead to preferential orientations in solution. While preferential orientation may contribute to the quinary structure in vivo, it has the very practical consequence of contributing to the high viscosity observed in some protein formulations (Yadav et al. 2012). Thus, chargecharge interactions have both fundamental and practical importance.

In 2004, Don published an important paper (Winzor 2004) whose title, "Determination of the net charge (valence) of a protein: a fundamental but elusive parameter", suggested that measuring protein charge accurately was not yet possible. In that paper, he emphasized that protein charge may not be calculated using current models, regardless of their sophistication, since proteins are known to bind significant quantities of monovalent anions other than $\mathrm{H}^{+}$. He enumerated a number of methods for estimating protein charge, citing the difficulties 
for each method, arriving at the gloomy prospect implied by the paper's title.

Electrophoresis provides the simplest method for estimating protein valence, since $\mu=\frac{z_{e f f}}{f Q_{p}}$, where $\mu$ is the electrophoretic mobility, $z_{\mathrm{eff}}$ is the effective valence, $f$ is the translational friction coefficient, and $Q_{\mathrm{p}}$ is the fundamental proton charge. Both $\mu$ and $f$ are measurable quantities, so $z_{\text {eff }}$ may be measured from knowing these two values. Alternatively, $z_{\text {eff }}$ may be determined directly from an experiment using steady-state electrophoresis. The justifiable concern Don expressed is that $z_{\text {eff }}$ is a system parameter, dependent on solvent properties, particularly ionic strength, and, therefore, obtaining the valence of the protein, $z_{\mathrm{p}}$, requires the use of a model. For example, the Debye-Hückel-Henry model treats the protein as an impenetrable sphere with the charge at its center. There are more rigorous, complicated models, however, using steadystate electrophoresis Durant et al. (2002) showed that, to within the uncertainty of the measurements $(5-10 \%), z_{\mathrm{DHH}}=z_{\mathrm{p}}$. These calculations used the sum of the protein and counterion Stokes radii, rather than the protein's van der Waal's radius, in the belief that any ions contained within the Stokes radius are part of the protein's charge structure. That is, $z_{\mathrm{p}}$ is the net charge of the volume defined by the Stokes radius and not the charge of the object defined by the van der Waal's surface. The uncertainty that remains, though, is that there are no absolute methods for protein charge measurement in solution, so the question of whether protein charge may be determined accurately by electrophoresis cannot be answered unequivocally. We are left in a quandary. However, based on the premise that $z_{\mathrm{p}}$ is the charge contained in a hypothetical volume defined by the Stokes radius, Filoti et al. proposed that $z_{\mathrm{DHH}}$ is an accurate estimate of $z_{\mathrm{P}}$ if the Debye-Hückel cloud is considered to be the solvent response to $z_{\mathrm{P}}$ (Filoti et al. 2015).

There are some important lessons about protein charge that are currently not widely appreciated. It has been shown that reasonable estimates of $z_{\mathrm{P}}$ are obtained from electrophoretic measurements for RNase A (Moody et al. 2005) and hen egg white lysozyme (Gokarn et al. 2011), both of which exhibit monovalent anion binding. Song's group at the University of Singapore have characterized monovalent anion binding by NMR (Miao et al. 2011). Both $z_{\text {eff }}$ and NMR measurements reveal that the relative binding strength of anions follows the Hofmeister series (Gokarn et al. 2011), suggesting that charge neutralization may be an important contributor to solubility. Donnan measurements and electrophoresis measurements reveal that serum albumin, a rather anionic protein, binds monovalent anions.

It is clear from all of the work to date that concomitant $\mathrm{H}^{+}$ and anion binding may occur (i.e., proteins may bind $\mathrm{H}^{+}: \mathrm{Cl}^{-}$ rather than just $\mathrm{H}^{+}$). While this observation may seem both novel and trivial, it is neither. In the 1950s, some of the great protein chemists recognized that proteins bind monovalent anions. Perhaps because of the advances in protein structure determination, the charge structure of proteins was neglected long enough that we forgot what these scientists showed us. To date, we do not know what the "rules" are for anion binding. Are there particular protein features or functional groups involved? The NMR results suggest that any class of amino acids may bind with apparent $\mathrm{K}_{d} \mathrm{~S}$ in the $\mathrm{mM}$ range, and that the nature of the side chain merely modulates the strength of binding. In any case, there are currently no methods for calculating protein charge from a protein structure, since all current models consider only $\mathrm{H}^{+}$binding.

Protein charge has very real practical importance, too. Charge-charge repulsion is important to the colloidal stability of high-concentration solutions of monoclonal antibodies. Moreover, charge-dipole and dipole-dipole interactions may lead to the asymmetrical alignment of proteins in highconcentration protein solutions, thus resulting in high viscosities (Yadav et al. 2012).

Of course, proteins are not the only charged biological macromolecules. Work done in my lab has shown that reasonable valences are obtained for DNA oligonucleotides and lipid nanodiscs (Her et al. 2016). In both of these cases, the charge groups may be closer than the Bjerrum length, leading to polyelectrolyte behavior. If we are to have accurate models of how biological molecules interact, we will need to measure the actual charge on the molecules and not rely on untested models.

In closing, I suggest that the valence of proteins (and other macromolecules) may be best estimated, with reasonable accuracy, by electrophoretic measurements. Given the importance of charge to the behavior of proteins in highconcentration solutions, it is imperative that such charge measurements become routine.

Note on the author Thomas Laue (Tom) received an undergraduate degree in Natural Sciences from Johns Hopkins University in 1971. After working for NASA for several years, Tom Laue returned to school and earned his $\mathrm{PhD}$ in 1980 at the University of Connecticut with David Yphantis developing a real-time interferometric detector for the analytical ultracentrifuge. Tom is an Emeritus Professor at the University of New Hampshire, where he has taught for 32 years. In 2001, Dr. Laue founded the Biomolecular Interaction Technologies Center (BITC) as a National Science Foundation Industry/University Cooperative Research Center. The BITC is a consortium of global pharmaceutical firms whose fees support university research and development of novel techniques and technologies for characterizing molecular interactions. Like Don, Tom has always been interested in how proteins interact in complex, highconcentration fluids. Much of his work has focused on determining whether electrophoretic charge measurements are accurate, not simply precise, and exploring the charge properties of biomacromolecules. Tom's work on charge determination 
has been receiving increasing interest with the relatively recent appreciation that charge is arguably the most important parameter in determining the solubility of monoclonal antibodies and other therapeutic proteins. The author hopes that the importance of charge to biology will be recognized and explored by others in the future.

\section{Compliance with ethical standards}

Conflict of interest Thomas Laue declares that he has no conflicts of interest.

Ethical approval This article does not contain any studies with human participants or animals performed by the author.

\section{References}

Durant JA, Chen C, Laue TM, Moody TP, Allison SA (2002) Use of T4 lysozyme charge mutants to examine electrophoretic models. Biophys Chem 101-102:593-609

Filoti DI, Shire SJ, Yadav S, Laue TM (2015) Comparative study of analytical techniques for determining protein charge. J Pharm Sci 104:2123-2131
Gokarn YR, Fesinmeyer RM, Saluja A, Razinkov V, Chase SF, Laue TM, Brems DN (2011) Effective charge measurements reveal selective and preferential accumulation of anions, but not cations, at the protein surface in dilute salt solutions. Protein Sci 20:580-587

Her C, Filoti DI, McLean MA, Sligar SG, Ross JBA, Steele H, Laue TM (2016) The charge properties of phospholipid nanodiscs. Biophys J 111:989-998

McConkey EH (1982) Molecular evolution, intracellular organization, and the quinary structure of proteins. Proc Natl Acad Sci U S A 79:3236-3240

Miao L, Qin H, Koehl P, Song J (2011) Selective and specific ion binding on proteins at physiologically-relevant concentrations. FEBS Lett 585:3126-3132

Monteith WB, Cohen RD, Smith AE, Guzman-Cisneros E, Pielak GJ (2015) Quinary structure modulates protein stability in cells. Proc Natl Acad Sci U S A 112:1739-1742

Moody TP, Kingsbury JS, Durant JA, Wilson TJ, Chase SF, Laue TM (2005) Valence and anion binding of bovine ribonuclease A between pH 6 and 8. Anal Biochem 336:243-252

Winzor DJ (2004) Determination of the net charge (valence) of a protein: a fundamental but elusive parameter. Anal Biochem 325:1-20

Yadav S, Laue TM, Kalonia DS, Singh SN, Shire SJ (2012) The influence of charge distribution on self-association and viscosity behavior of monoclonal antibody solutions. Mol Pharm 9:791-802 